\title{
Two Ocean Tides per Day: Why?
}

\section{Kern E. Kenyon}

Del Mar, CA, USA

Correspondence to: Kern E. Kenyon, kernken@aol.com Keywords: Semidiurnal Ocean Tides, Vertical Tidal Forces

Received: October 5, $2020 \quad$ Accepted: November 10, $2020 \quad$ Published: November 13, 2020

Copyright $\odot 2020$ by author(s) and Scientific Research Publishing Inc.

This work is licensed under the Creative Commons Attribution International License (CC BY 4.0).

http://creativecommons.org/licenses/by/4.0/

\section{Open Access}

\section{ABSTRACT}

Ocean semi-diurnal tides are suggested qualitatively to be more accurately explained by the vertical tide generating forces of the sun and moon, not by the historically standard horizontal components. It is proposed that the sea level elevations created sequentially at the eastern and then western ocean coastal boundaries propagate seaward as shallow water surface gravity waves and interact without mutual disturbance. In that manner two tides per day are created. Horizontal tide forces generate horizontal ocean currents with speeds of $5 \mathrm{mph}$ at the most. Shallow water tide waves move at about $500 \mathrm{mph}$ in open waters and therefore come much closer to being in tune with the sun and moon transiting across the sky.

\section{INTRODUCTION}

From most tide gauges in most oceans comes the information that there are two high tides and two low tides in one day. Why? This observation is counter-intuitive since the sun and the moon pass over each tide gauge only once a day, and it is universally accepted that the gravitational attractions of the sun and moon are what causes ocean tides. Explanations exist but all the authors [1-4], for some reason, have fixated on the horizontal component of the tide force by tradition. Here the focus is on the vertical component of the tide force to help understand the two tides per day dilemma. Incidentally both tide force components have the same magnitude.

A horizontal tide force is expected to create or make a change in a horizontal current. Supposedly these horizontal currents then somehow and somewhere converge to form high tides. At this point imagination fails. Behind the failure is a fact: open-ocean horizontal currents are at least 100 times slower than a propagating shallow water surface gravity wave is, which has a speed of about $500 \mathrm{mph}$. For example, it is well known from timing after an earthquake and arrival at a coast that tsunamis move across the ocean at about $500 \mathrm{mph}$, and they are shallow water waves, as are the tides. One of the fastest currents in the open ocean, the Gulf Stream, flows at $5 \mathrm{mph}$. Another reference speed is that the sun and moon pass over a fixed point on the earth's surface at about $1000 \mathrm{mph}$.

A shallow water surface gravity wave has a wavelength much greater than the mean depth of water, and its speed is proportional to the square root of the mean depth. Even at $4 \mathrm{~km}$, the mean depth of most 
oceans away from coasts, the tides certainly qualify to be shallow water waves.

One additional fundamental and helpful idea is that a fluid has the property of flowing in the direction of the least amount of force. So the relatively small vertical tide force should make the surface of the sea elevate directly. Once an elevation is produced, a wave like movement of it can take place.

\section{ARGUMENT}

Consider the North Pacific Ocean and let it be night time on the U.S. west coast. As the sun rises the water at the shore begins to feel the vertical force of gravitational attraction. Gradually the sea level responds by rising, first at the shore so that a westward slope to the sea surface develops. Sometime before the sun is straight up at the beach the sloping sea level starts migrating to the west with the speed of a shallow water surface gravity wave.

Since the sun travels west at about double the shallow water wave speed, at deep water depths, it leaves the solitary wave behind and stops increasing its sea level any further.

On the sun's approach to the west coast of the North Pacific the sea level at that location senses the vertical tide force and starts to rise. Essentially the reverse of the situation that occurred earlier off the U. S. west coast now takes place there, resulting in a solitary wave heading east as the sun leaves the ocean behind. Extrapolating from lab experiments in Scotland [5], the two oppositely directed solitary waves could meet, move through each other without disturbance to either one, and continue on their separate ways. Therefore, two high and two low tides are predicted to happen during one passage of the sun across the ocean.

Using Newton's gravitational force law and forming the vertical tide force $F_{S}$ by taking the difference between that at the ocean's surface facing the sun and that at the earth's center gives

$$
F_{s}=G S E\left(\frac{2 r}{R^{3}}\right)
$$

where the masses of the sun and earth are $S$ and $E, r$ is the earth's radius, $R$ is the earth-sun distance and $G$ is the gravitational constant.

Similarly for the vertical tide force of the moon $F_{m}$

$$
F_{m}=G M E\left(\frac{2 r}{R_{0}^{3}}\right)
$$

where $R_{0}$ is the earth-moon distance and $M$ is the moon's mass. Dividing (2) by (1) produces the value of the ratio of the two vertical tide forces showing that the moon's is about 2.2 times the sun's when standard values of the constants are inserted. As mentioned above the horizontal tide forces have the same magnitudes as given by (1) and (2). These equations have been developed in some dynamical oceanography texts [6]. They are approximate because the squares of the ratios of the earth's radius to the earth-sun and the earth-moon distances are neglected in the derivations, but these assumptions are good ones.

\section{DISCUSSION}

Along the California coast the tides move from south to north. That is consistent with the present line of argument given the south-east to north-west orientation of the coastline.

One more consistency between theory and observations is offered. Lake Superior is a very large enclosed lake, which has measurable tides, but their amplitudes are small compared to those in the oceans. Since the depths of water in the lake are small compared to the $4 \mathrm{~km}$ ocean depth, the shallow water wave speeds are considerably slower. In Lake Superior the vertical tide force mechanism is not as efficient; both sun and moon go by too quickly relative to the wave speed.

\section{CONCLUSION}

A claim is made that the puzzling observation of two tides per day in most oceans can be understood 
more easily by starting with the vertical components of the tide generating forces of the moon and the sun rather than the horizontal components as are usually done. Propagation of the resulting tidal elevation as a shallow water surface gravity wave in the deep ocean, from opposing (eastern and western) continental boundaries is also central to the explanation.

\section{CONFLICTS OF INTEREST}

The authors declare no conflicts of interest regarding the publication of this paper.

\section{REFERENCES}

1. Cartwright, D. (1999) Tides: A Scientific History. Cambridge University Press, Cambridge.

2. Darwin, G.H. (1899) The Tides and Kindred Phenomenon in the Solar System. Houghton, Boston.

3. Proudman, J. (1953) Dynamical Oceanography. John Wiley and Sons, New York.

4. Wikipedia (2020) Tides.

5. Russell, J.S. (1844) Report on Waves. Report of the Fourteenth Meeting of the British Association for the Advancement of Science, York, September 1844.

6. Duxbury, A.C. (1971) The Earth and Its Oceans. Addison-Wesley, Menlow Park, CA, Ch. 17. 